\title{
FINITE ELEMENT ANALYSIS OF THE MODIFIED TURRET LIFTING
}

\section{HOOKS OF COMBAT VEHICLE}

\section{RAMEEZA ${ }^{1}$, S. A. MUHAMMED ABRAAR ${ }^{2}$, N. SURESH ${ }^{2}$, D. SANTHOSH ${ }^{2} \&$ B. RAMESH ${ }^{2}$}

${ }^{1}$ Senior Research Fellow, Combat Vehicles Research \& Development Establishment, Chennai, Tamil Nadu, India

${ }^{2}$ Department of Mechanical Engineering, St. Joseph's Institute of Technology, Chennai, Tamil Nadu, India

\section{ABSTRACT}

Finite element model of Weld assembly of the Turret Lifting Hooks of the Combat Vehicle at the modified positions is prepared from the assembly solid model. The solid geometry of the weld assembly has meshed with 10 node C3D10 quadratic tetrahedron elements. Common nodes shared by the Turret Lifting Hooks and the Welds and by the Welds and the Plates are merged, in order to ensure the connectivity of the respective components with the respective welds.

Analysis has been done for two load cases as mentioned below:

Load Case 1: Non-linear Static analysis of the Turret Lifting Hooks welding assembly of Combat Vehicle applied with a vertical hanging load of 215820 N (22 Tons) at the CG of Turret \& Weapon System (TWS) in order to simulate gradual lifting of the TWS.

Load Case 2: Non-linear Static analysis of the Turret Lifting Hooks welding assembly of Combat Vehicle applied with a vertical hanging load of $215820 \mathrm{~N}$ (22 Tons) at the CG of TWS in order to simulate sudden lifting of the TWS.

From the results of the above said analysis of the weld assembly of Combat Vehicle Turret Lifting Hooks, it has been observed that in the Load case 1, the critical stress value in the Lifting Hooks Front, LH side and RH side are 486 MPa, 433.4 MPa, and 411.4 MPa respectively and peak stress values in the Welds of the Lifting Hook Front, LH and $\mathrm{RH}$ are 98.3 MPa, 177.9 MPa and 177.4 MPa respectively. Whereas the yield limit of the Turret Lifting Hooks material (Homogenous weldable steel armor to SPC CDA-99) is $800 \mathrm{MPa}$. Hence the stress induced is clearly less than the yield value of the material.

KEYWORDS: Turret Lifting Hooks Welding Assembly, Gradual Lifting, Sudden Lifting, Turret \& Weapon System (TWS)

Received: Sep 28, 2018; Accepted: Oct 18, 2018; Published: Dec 14, 2018; Paper Id.: IJMPERDDEC201877

\section{INTRODUCTION}

The lifting hooks are used to lift the entire Turret \& Weapon System (TWS) assembly. [1] provides the ASME Standard for Cranes [2] provides the "Slings Safety Standard for Cableways, Cranes, Derricks, Hoists, Hooks, Jacks and Slings" [3] provides the "Hooks Safety Standard for Cableways, Cranes, Derricks, Hoists, Hooks, Jacks and Slings," [4] provides the "Approved Code of Practice for Cranes," [5] B. Ross, B. McDonald and S. E. V. Saraf studied the Engineering Failure Analysis [6] Yu Huali, H.L. and Huang Xieqing found out the Structure-strength of Hook with Ultimate Load by Finite Element Method [7] A P Boresi and O M Sidebottam, 
John Wiley and Sons studied the Advanced Mechanics of Materials [8] provides the details of the Lifting hooks for lifting appliances; single hooks; Unmachined parts [9] Rashmi Uddanwadiker states that stress of Crane Hook is within the limit and it is Validated by Photo-Elasticity [10] Sadhu Singh studied the "Strength of Materials" [11] Deutsche Norm studied the Lifting hooks; materials, mechanical properties, lifting capacity and stresses.

The lifting hooks of a Combat Vehicle are modified. In order to lift the MBT turret, three hooks are welded to the Turret top plate. One hook is welded to the front portion of the top of the turret structure and other two hooks are welded in the rear portion of the top of the turret structure, one in the LH side and the other in the RH side. In order to ensure full opening of the lids of the new bins, the position of the turret lifting hooks in the rear portion of the roof plate has been modified by about $120 \mathrm{~mm}$ along the present plane of welding. But in that design, since the total lifting load is fully shared by the welds, a new hook design has been proposed and now that has been taken for analysis. Turret lifting is being carried out by connecting two slings of length $2300 \mathrm{~mm}$ to the two rear turret lifting hooks and an adjustable tie rod with a maximum length of $1750 \mathrm{~mm}$ to the front turret lifting hook.

\section{DESCRIPTION OF THE MODEL}

Out of the three lifting hooks, there is no change in the existing front lifting hook, but the design of the rear lifting hooks has been modified. One of the existing rear lifting hooks with turret plates is shown in Figure 1. In the existing design, the rear lifting hook is having an integral base which is in level with the turret plates and provided with necessary chamfers for welding, both on the lifting hook and on the turret plates.

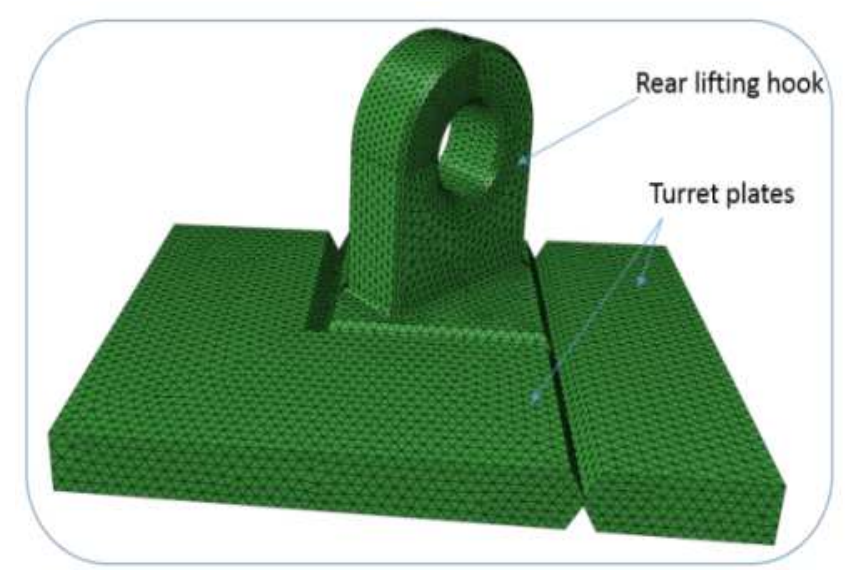

Figure 1: Existing Rear Hook with Turret Plates

The rear hook is now modified such that it can be inserted from the bottom of the turret top plate, so that rear hook can be welded on the top of the turret plate and also at the bottom of the turret plate. In order to give access to the rear hook, a slot has been cut in the turret top plate. Modified rear hook and the slot cut in the turret plate are shown in the Figures 2 and 3respectively. 


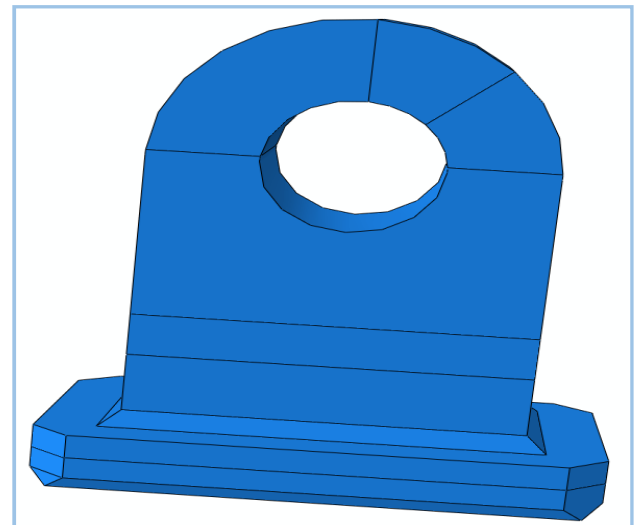

Figure 2: Modified Rear Hook

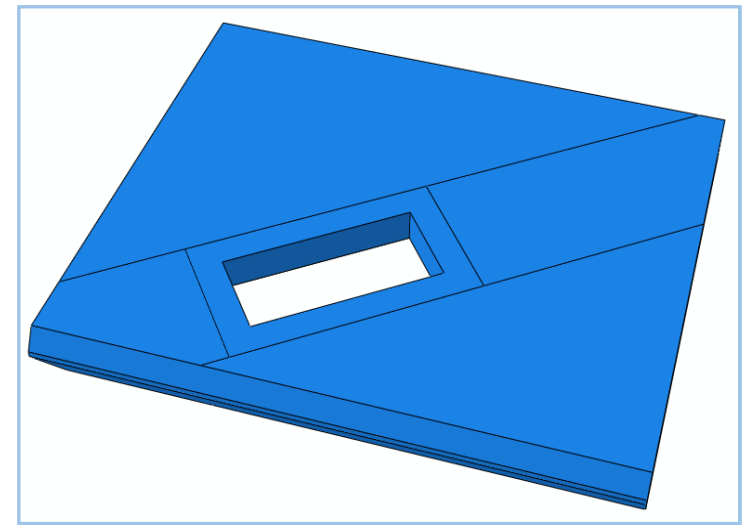

Figure 3: Slot Cut in the Turret Plate

Assembly of the rear hook and the turret plate is shown in Figure 4. In the assembled condition the rear hook is welded with the turret top plate with $15 \mathrm{~mm}$ fillet weld on the top and $8 \mathrm{~mm}$ fillet weld at the bottom.

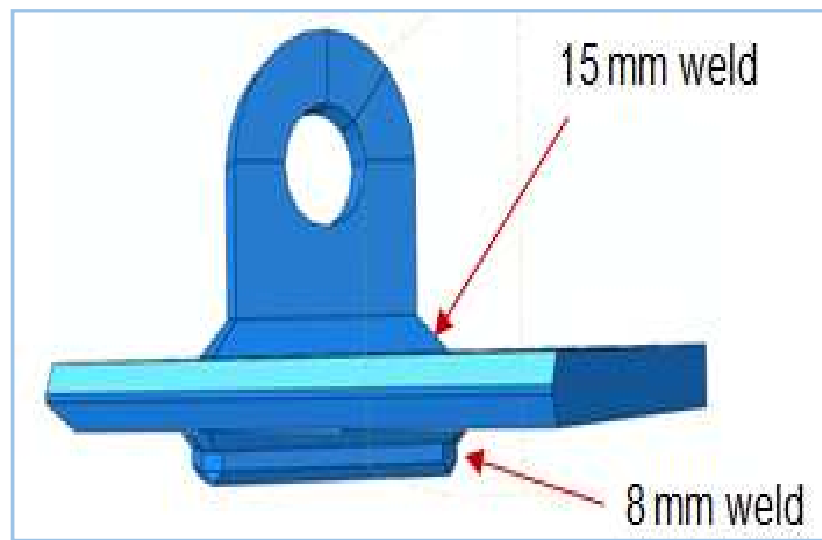

Figure 4: Assembly of Rear Hook with Turret Plate

Figure 5 shows the front lifting hook welded on the turret structure and with the D-shackle pin. As said earlier there is no change in the front hook assembly.

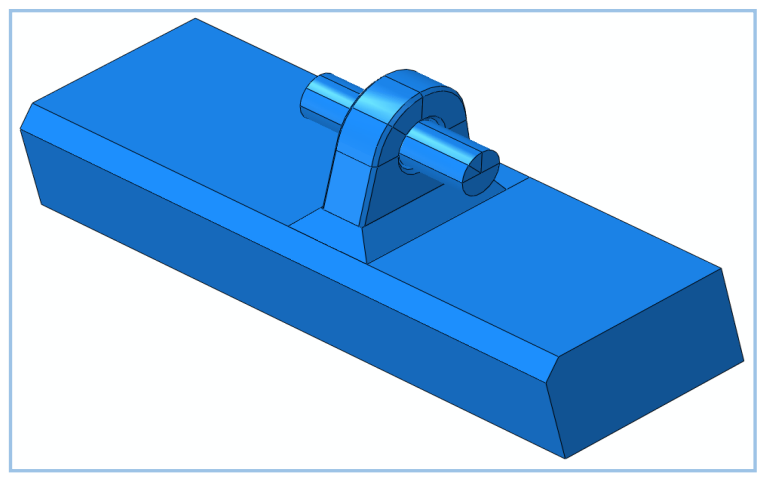

Figure 5: Assembly of Front Hook on the Turret with the D-Shackle Pin

\section{MATERIAL DATA}

Mechanical properties of materials of the Roof plate, Turret Lifting Hook and the D-Shackle Pin are shown in the following Tables 1 and 2 . 
Table 1: Material of Roof Plate \& Turret Lifting Hooks

\begin{tabular}{|l|c|}
\hline $\begin{array}{c}\text { Material of Roof Plate \& } \\
\text { Turret Lifting Hooks }\end{array}$ & $\begin{array}{c}\text { Homogenous Weldable Steel Armour to } \\
\text { SPC CDA-99 }\end{array}$ \\
\hline Ultimate tensile strength & $900 \mathrm{MPa}$ \\
Yield strength & $800 \mathrm{MPa}$ \\
Modulus of elasticity & $2.1 \times 10^{5} \mathrm{MPa}$ \\
Poisson's ratio & 0.3 \\
Density & $7850 \mathrm{~kg} / \mathrm{m}^{3}$ \\
\hline
\end{tabular}

Table 2: Material of D-Shackle Pin

\begin{tabular}{|l|c|}
\hline Material of D-Shackle Pin & $\begin{array}{c}\text { Steel Forging to BS:970, 826M31 (En25), } \\
\text { COND-X }\end{array}$ \\
\hline Ultimate tensile strength & $1158 \mathrm{MPa}$ to $1314 \mathrm{MPa}$ \\
Yield strength & $1020 \mathrm{MPa}$ \\
Shear Yield strength & $534 \mathrm{MPa}$ \\
Modulus of elasticity & $2.1 \times 10^{5} \mathrm{MPa}$ \\
Poisson's ratio & 0.3 \\
Density & $7850 \mathrm{~kg} / \mathrm{m}^{3}$ \\
\hline
\end{tabular}

\section{FINITE ELEMENT MODELING}

The main assembly of the three turret lifting hooks welded on the turret top plate is disintegrated into three local assemblies in this analysis. Each local assembly, containing the Turret Lifting Hook, Roof plate, D-Shackle pin, and the Weld fillets, is modeled with C3D10 - 10 node quadratic tetrahedral elements. Common nodes shared by the Turret Lifting Hook and the weld and by the Turret top plate and the weld are merged, in order to ensure connectivity of the respective components with the respective weld. Contact is defined between the Turret Lifting Hook and the D-Shackle Pin in all the three hook assemblies. A reference point is created at the Crane Hook location where all the three slings are connected to lift the Turret. This reference point is connected to the three D-Shackle pins using rigid couplings. One more reference point is created at the Centre of Gravity of the Turret and Weapon System (TWS) wherein the TWS mass of 22 Tons is lumped as a three-dimensional mass element. Three small plates in the three local assemblies of Turret Lifting Hooks are connected to this reference point (TWS CG) using rigid couplings. Hence a finite element model representing all the components and the weld features is shown in the following Figure 6.

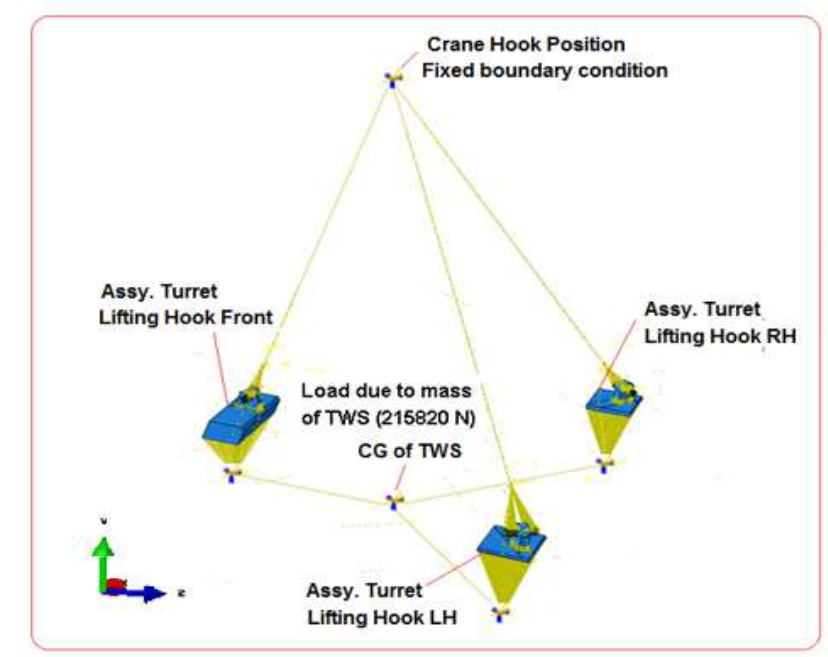

Figure 6: Finite Element Model of the Welding of Three Turret Lifting Hooks 
In this analysis, the reference point representing the Crane Hook position is restrained to move in all the degrees of freedom. Load due to gravitational acceleration is applied to the whole assembly in order to represent the load due to the mass lumped at the CG of the Turret and Weapon System. Three small plates in the three local assemblies of Turret Lifting Hooks are connected to the reference point of TWS CG using rigid coupling locations are restrained to move in all the degrees of freedom, except the vertical degree of freedom along the y-direction.

\section{FINITE ELEMENT ANALYSIS}

Static analysis of the welded turret lifting hooks assembly setup has been carried out using the Finite element method with the above-specified loads and boundary conditions and a solution has been obtained for the following two load cases.

Load Case 1: Static analysis of the Turret Lifting Hooks welding assembly of Combat Vehicle applied with $1 \mathrm{~g}$ acceleration load due to gravity in the vertical direction, which will simulate a vertical hanging load of $215820 \mathrm{~N}$ (22 Tons) at the CG of TWS in order to represent gradual lifting of the TWS.

Load Case 2: Static analysis of the Turret Lifting Hooks welding assembly of Combat Vehicle applied with $2 \mathrm{~g}$ acceleration load due to gravity in the vertical direction in order to simulate sudden lifting of the TWS.

\section{RESULTS AND DISCUSSIONS}

Finite element static analysis of the Turret Lifting Hooks welding assembly including all the components along with the specified loads and boundary conditions is carried out. Results of the non-linear static analysis for the above said two load cases are as follows:

\section{Results of Load Case 1}

Turret Lifting Hooks welding assembly applied with a vertical hanging load of $215820 \mathrm{~N}$ (22 Tons) simulating Gradual Lifting.

As a result of Load case 1, resultant displacement of the Turret Lifting Hooks welding assembly due to 22 Tons of vertical load is $0.106 \mathrm{~mm}$ as shown in Figure 7. Resultant displacement distribution of the Lifting Hook assembly Front, Lifting Hook assembly LH and Lifting Hook assembly RH are shown in the Figures 8, 9 and 10. It may be noted that the peak stresses of 333.7 MPa, 510.2 MPa, and 454.5 MPa in the Lifting Hooks Front, LH and RH assemblies shown in the Figures 12 to 14, are highly localized due to the contact between the Hook and the D-Shackle pin which is also compressive contact stress. By removing the local effect, the Von-Mises stress distribution on all the three Lifting Hooks and on the welds are also shown in Figures 12 to 19. Peak stresses in the Lifting Hook Front, LH and RH are 154.9 MPa, 258.4 MPa, and 145.2 MPa, respectively. Peak stresses in the top welds of the Lifting Hook Front, LH and RH are 50.82 $\mathrm{MPa}, 78.88 \mathrm{MPa}$, and $203 \mathrm{MPa}$. Peak stresses in the bottom welds on the lifting hook LH and RH are 27.72 MPa and 50.16 MPa respectively. 


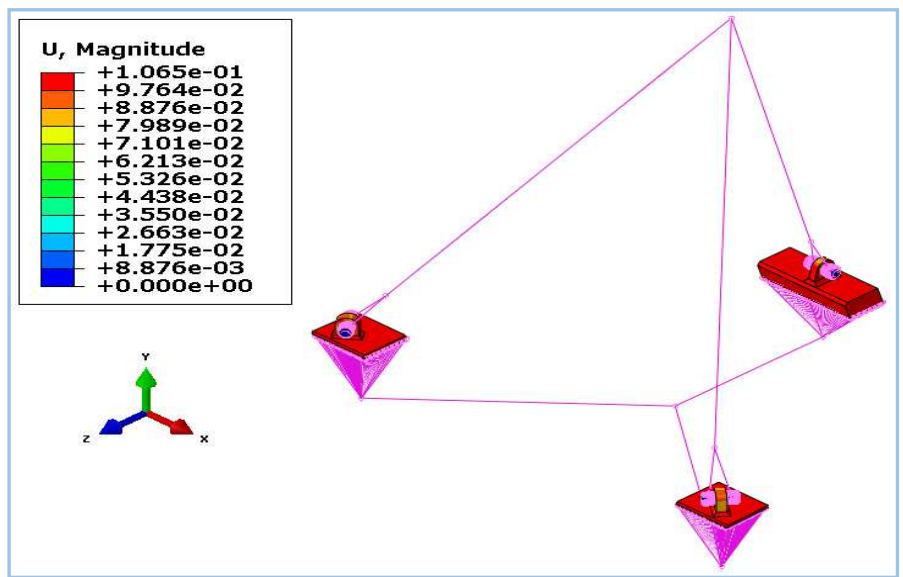

Figure 7: Resultant Displacement Distribution of the Turret Lifting Hooks Assembly Applied with 22 Tons of Lifting Load

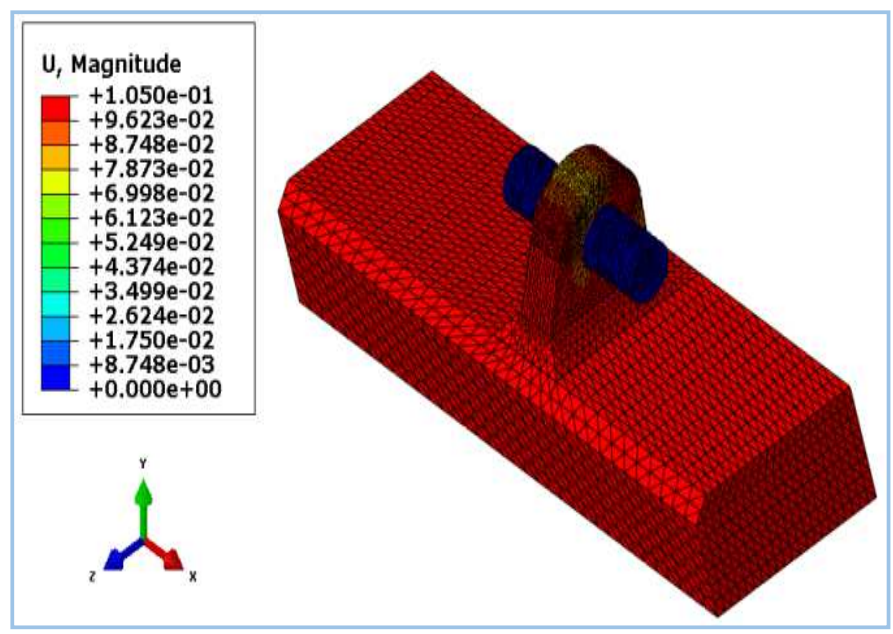

Figure 8: Resultant Displacement Distribution in the Turret Lifting Hook

Front Assembly

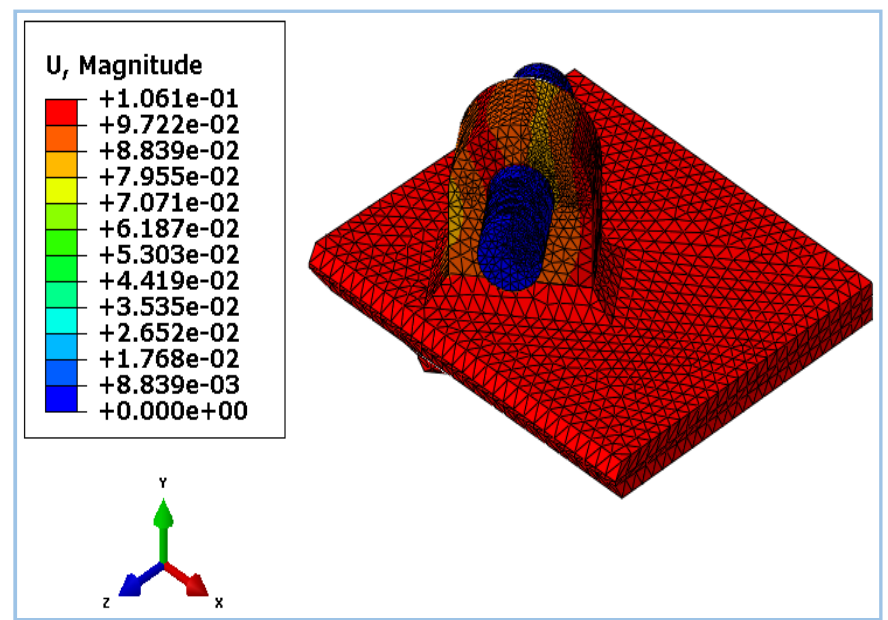

Figure 9: Resultant Displacement Distribution in the Turret Lifting Hook LH assembly 


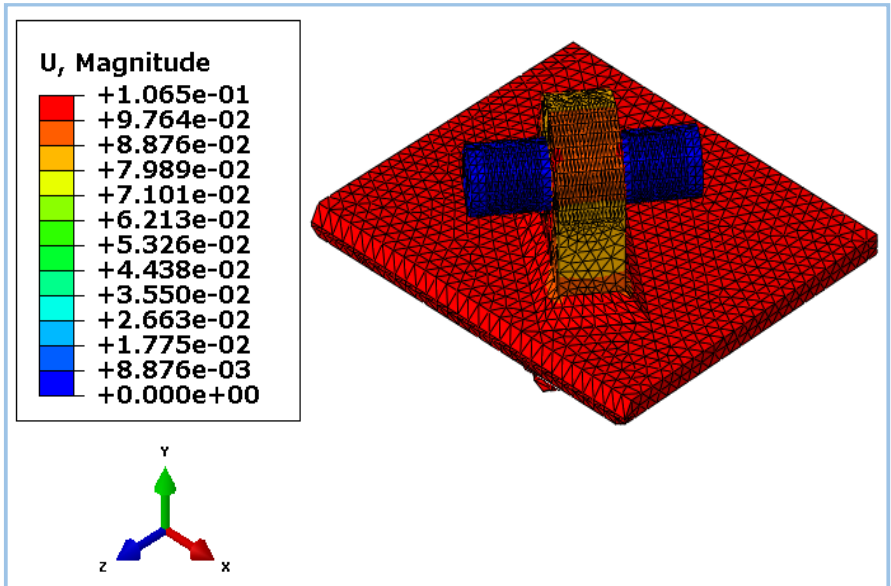

Figure 10: Resultant Displacement Distribution in the Turret Lifting Hook RH assembly

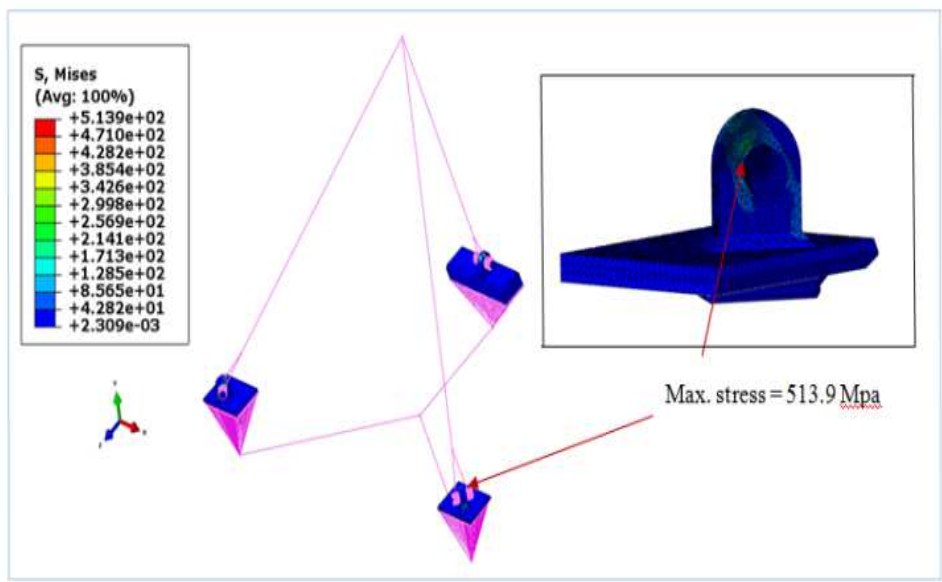

Figure 11: Max. Von-Mises Stress Distribution in the Turret Lifting Hook Assembly, Applied with 22 Tons of Lifting Load

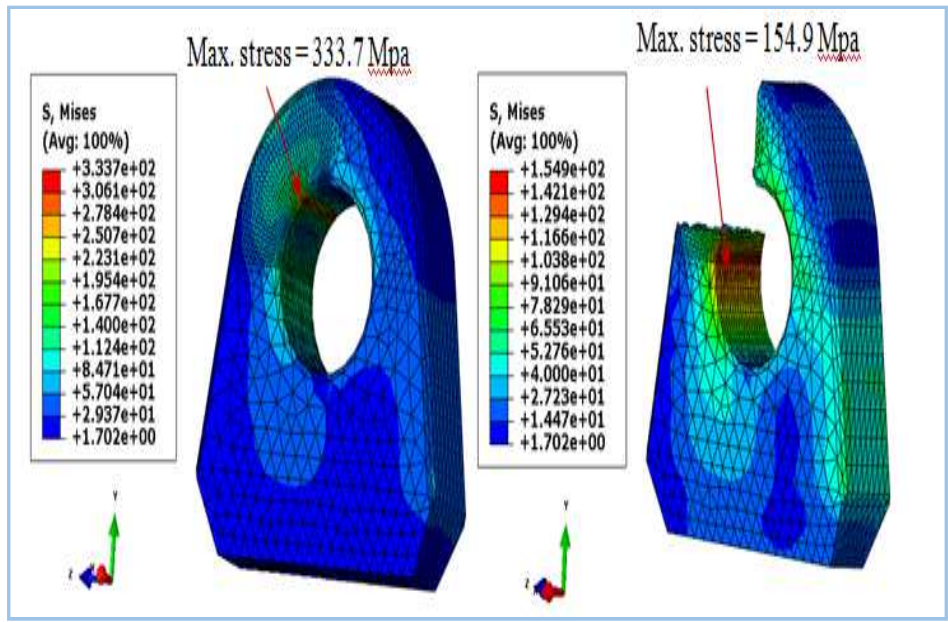

Figure 12: Stress Distribution in the Turret Lifting Hook Front 


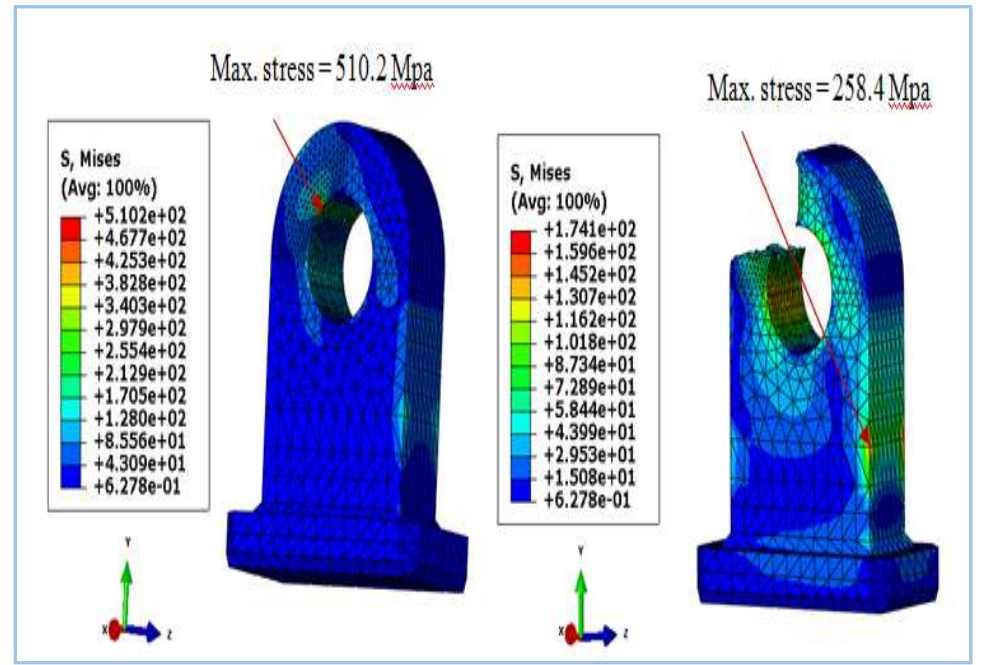

Figure 13: Stress Distribution in the Turret Lifting Hook LH

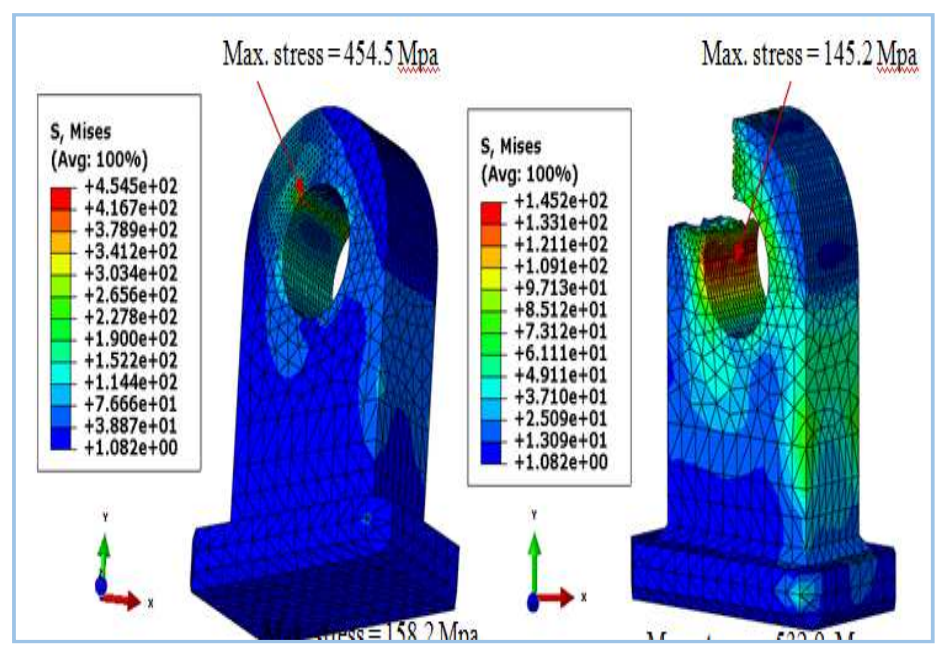

Figure 14: Stress Distribution in the Turret Lifting Hook RH

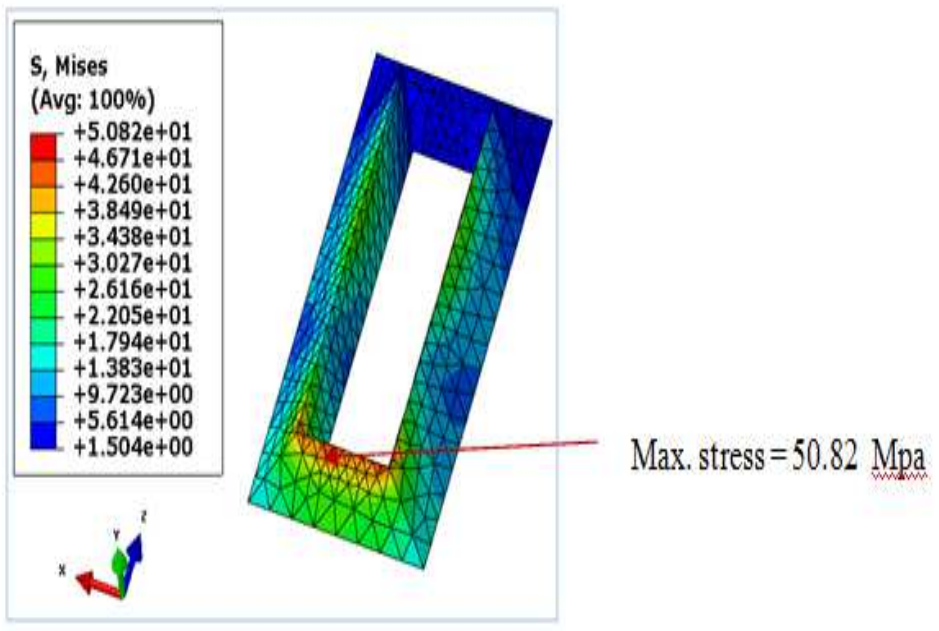

Figure 15: Von-Mises Stress Distribution in the Weld - Front Hook 


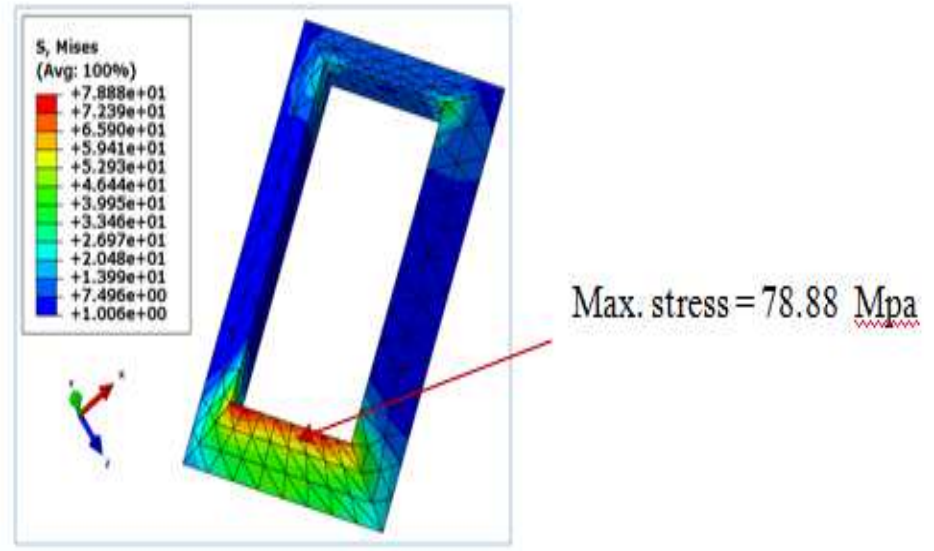

Figure 16: Von-Mises Stress Distribution in the Top Weld - LH Hook

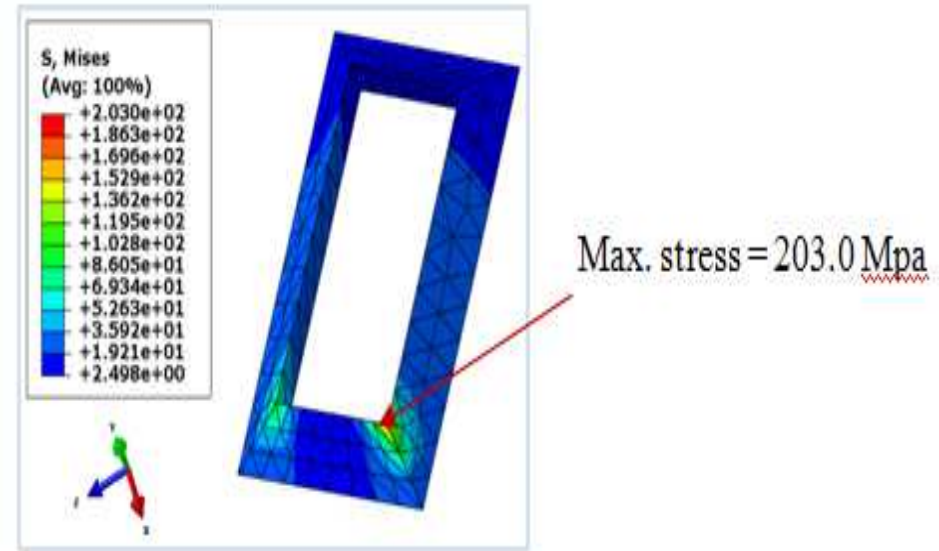

Figure 17: Von-Mises Stress Distribution in the Top Weld - RH Hook

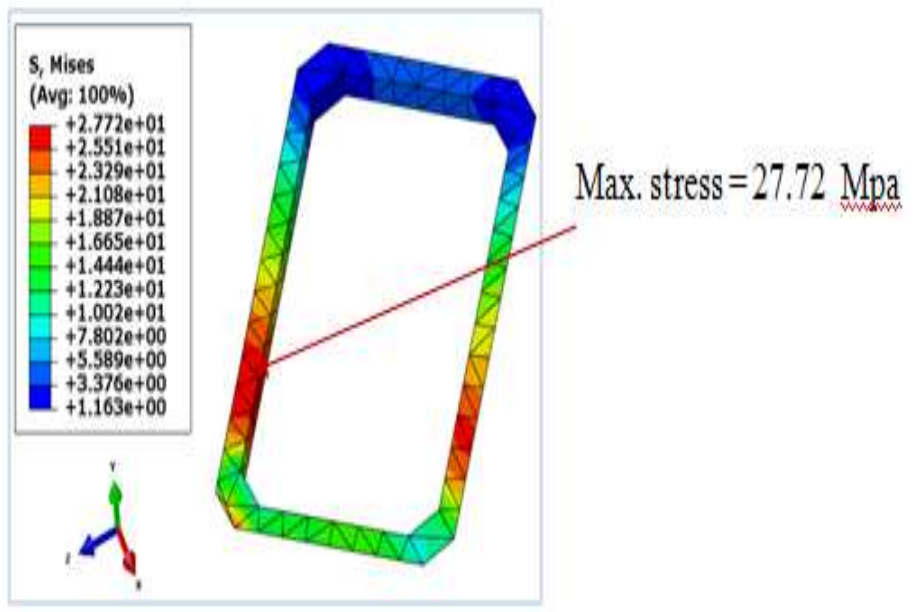

Figure 18: Von-Mises Stress Distribution in the Bottom Weld - LH Hook 


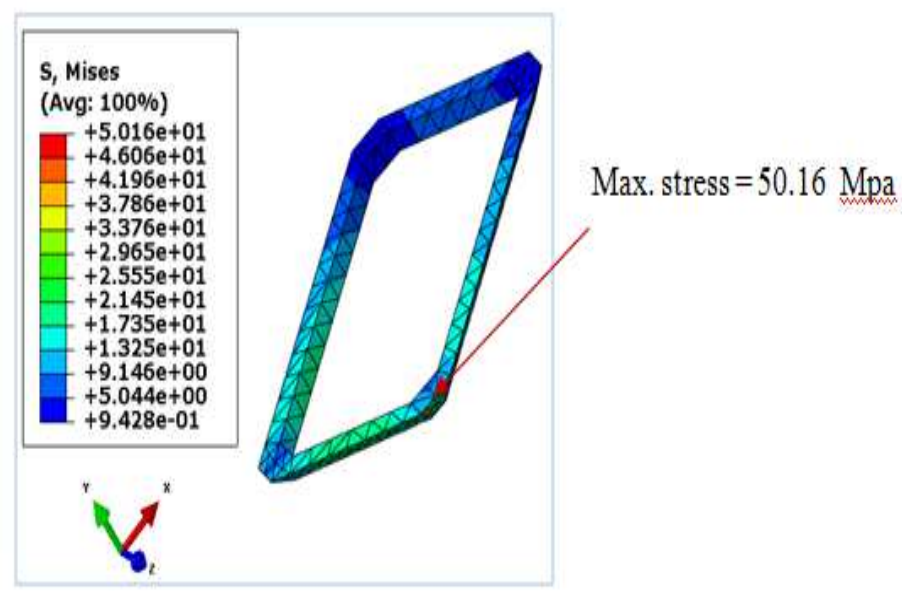

Figure 19: Von-Mises Stress Distribution in the Bottom Weld - RH Hook

As a result of Load case 1, the Von-Mises stress distribution on all the three D-Shackle pins for the Lifting Hooks and maximum principal stresses are shown in Figures 20 to 22. Peak Von-Mises stress in the D-Shackle pin Front, LH and $\mathrm{RH}$ are $474 \mathrm{MPa}, 602 \mathrm{MPa}$, and $554 \mathrm{MPa}$, respectively.

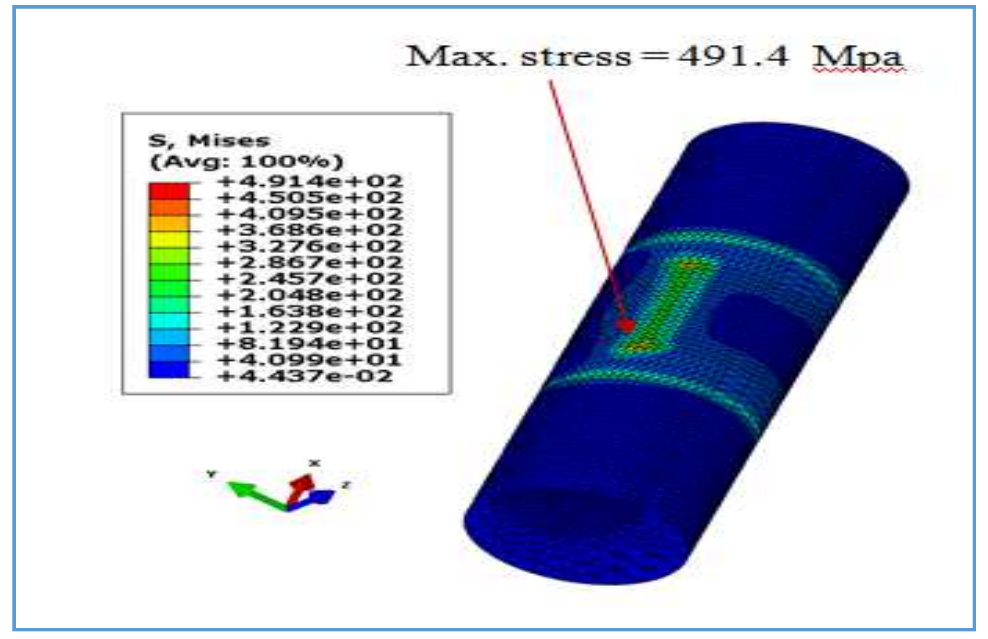

Figure 20: Stress Distribution in the D-Shackle Pin Front

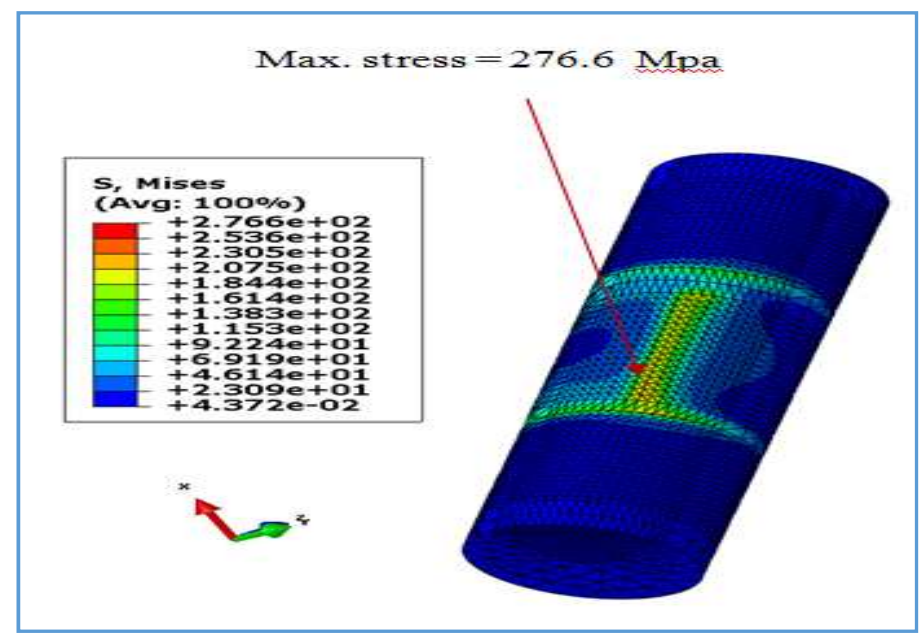

Figure 21: Stress Distribution in the D-Shackle Pin LH 


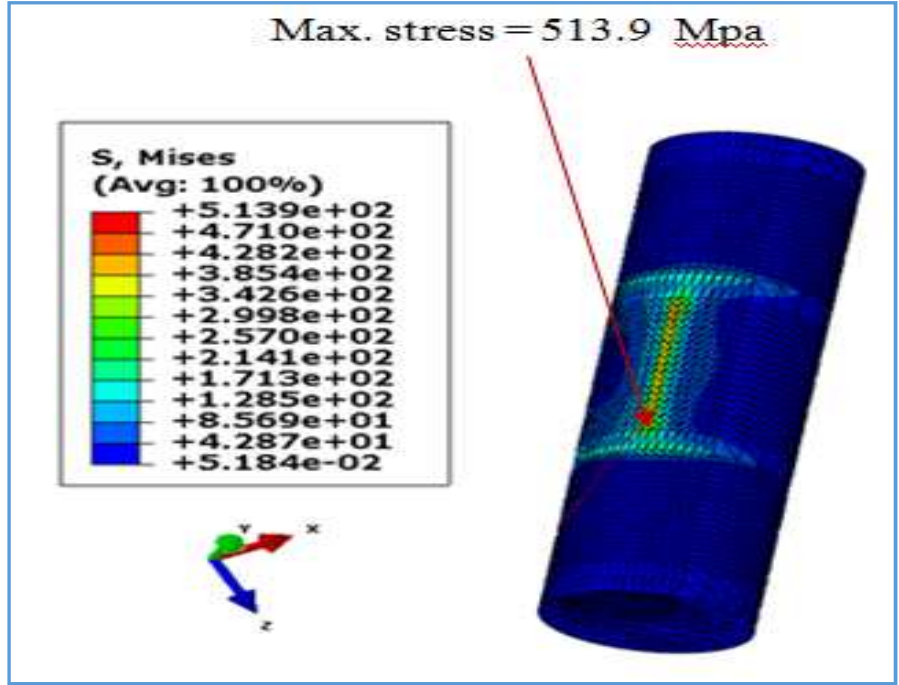

Figure 22: Stress Distribution in the D-Shackle Pin RH

\section{Results of Load Case 2}

Turret Lifting Hooks welding assembly applied with a load due to the sudden lifting of the vertical hanging load of $215820 \mathrm{~N}$ (22 Tons)

For sudden lifting, since the load data is not provided by the user group, on the conservative side, a load due to twice the gravitational force $(2 \mathrm{~g})$ is considered in this analysis.

As a result of Load case 2, resultant displacement of the Turret Lifting Hooks welding assembly is $0.221 \mathrm{~mm}$ as shown in Figure 23. Resultant displacement distribution of the Lifting Hook assembly Front, Lifting Hook assembly LH and Lifting Hook assembly RH are shown in the Figures 24 to 26. It may also be noted that the peak stress of 964 MPa is in the Lifting Hooks assembly Front is shown in Figure 27. But that value of stress is highly localized due to the contact between the Hook and the D-Shackle pin which is compressive contact stress. By removing the local effect, the Von-Mises stress on all the three Lifting Hooks and on the welds are shown in the Figures 28 to 35. Peak stresses in the Lifting Hook Front, LH and RH are $284 \mathrm{MPa}, 472 \mathrm{MPa}$, and $428 \mathrm{MPa}$, respectively. Peak stresses in the top welds of the Lifting Hook Front, $\mathrm{LH}$ and $\mathrm{RH}$ are $151 \mathrm{MPa}, 466 \mathrm{MPa}$, and $480 \mathrm{MPa}$. Peak stresses in the bottom welds on the lifting hook LH and RH are $119 \mathrm{MPa}$ and $122 \mathrm{MPa}$ respectively.

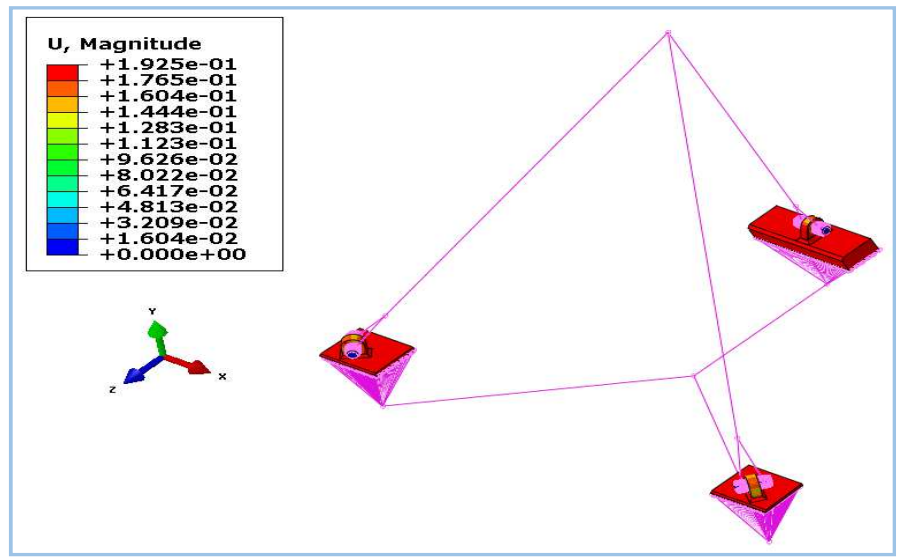

Figure 23: Resultant Displacement Distribution of the Turret Lifting Hooks Assembly Due to Sudden Lifting Load (Load Case 2) 


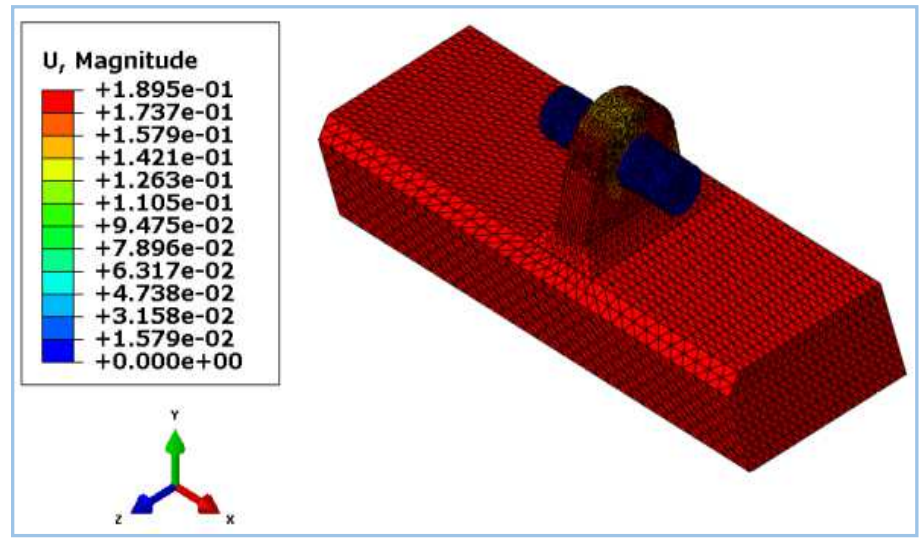

Figure 24: Resultant Displacement Distribution in the Turret Lifting Hook

\section{Front Assembly}

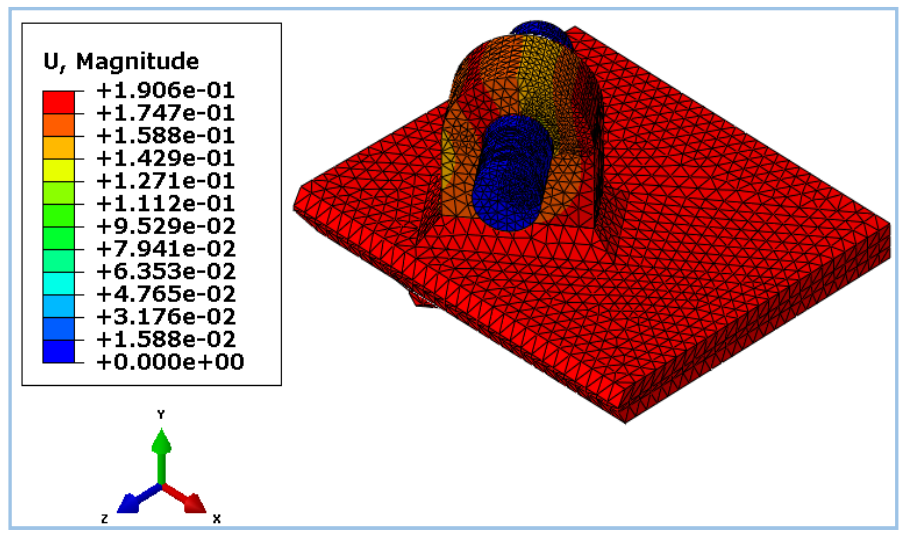

Figure 25: Resultant Displacement Distribution in the Turret Lifting Hook

LH Assembly

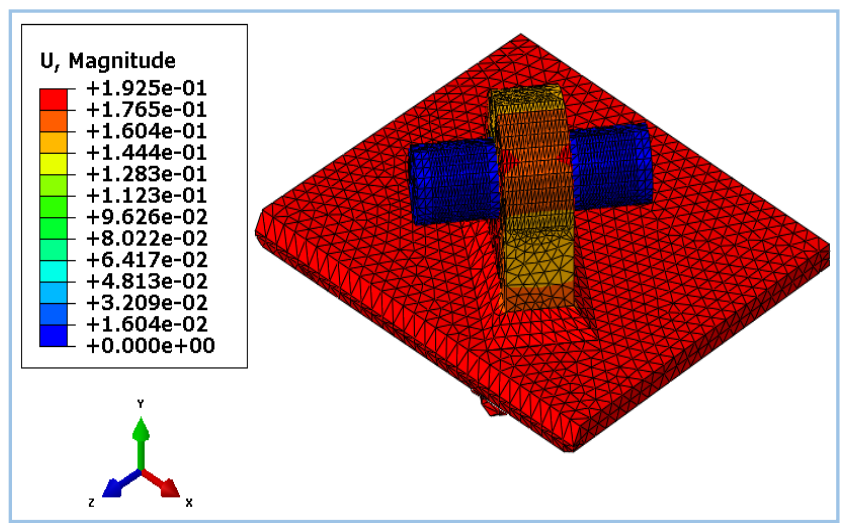

Figure 26: Resultant Displacement Distribution in the Turret Lifting Hook 
RH Assembly

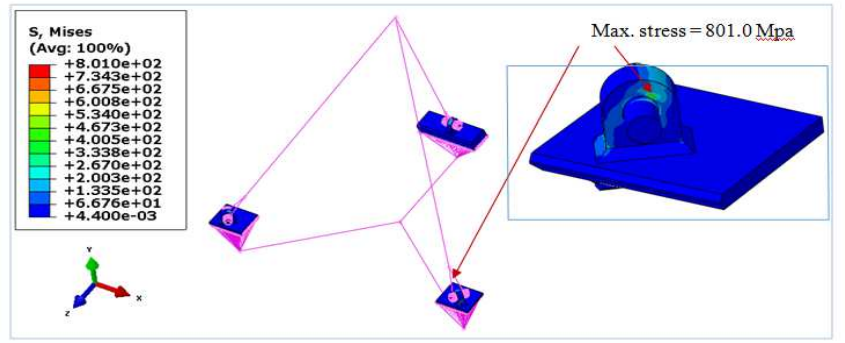

Figure 27: Von-Mises Stress Distribution in the Turret Lifting Hooks Assembly Due to Sudden Lifting Load (Load Case 2)

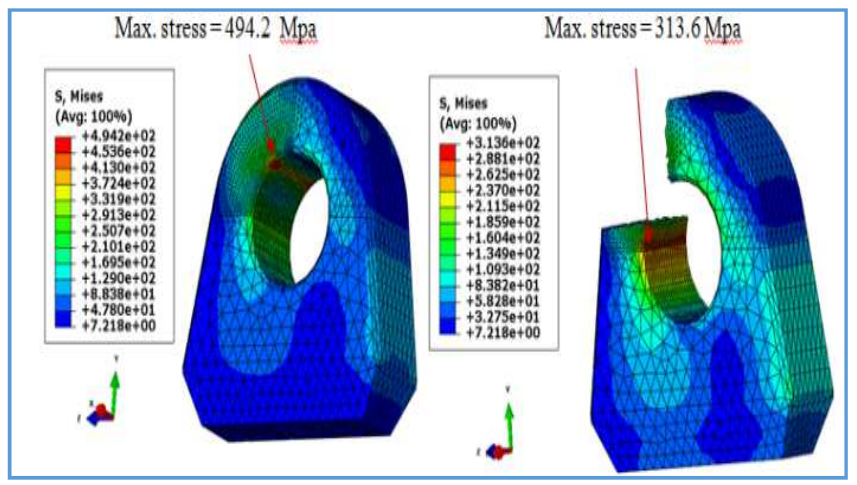

Figure 28: Stress Distribution in the Turret Lifting Hook Front

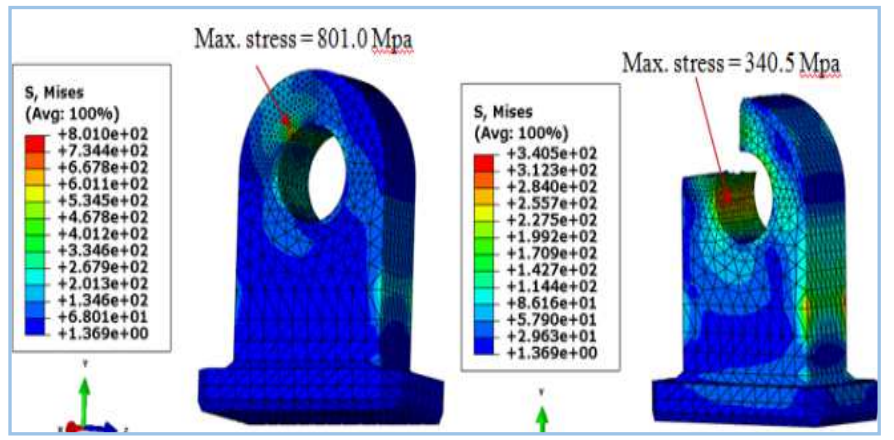

Figure 29: Stress Distribution in the Turret Lifting Hook LH

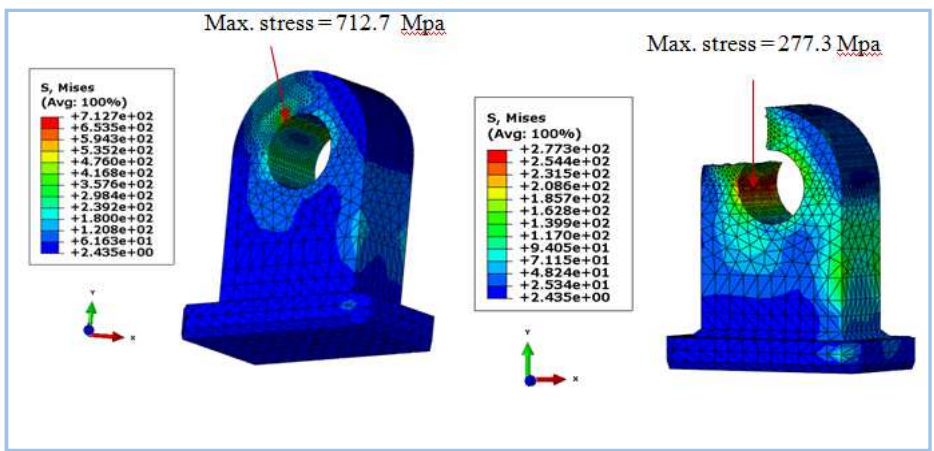

Figure 30: Stress Distribution in the Turret Lifting Hook RH 


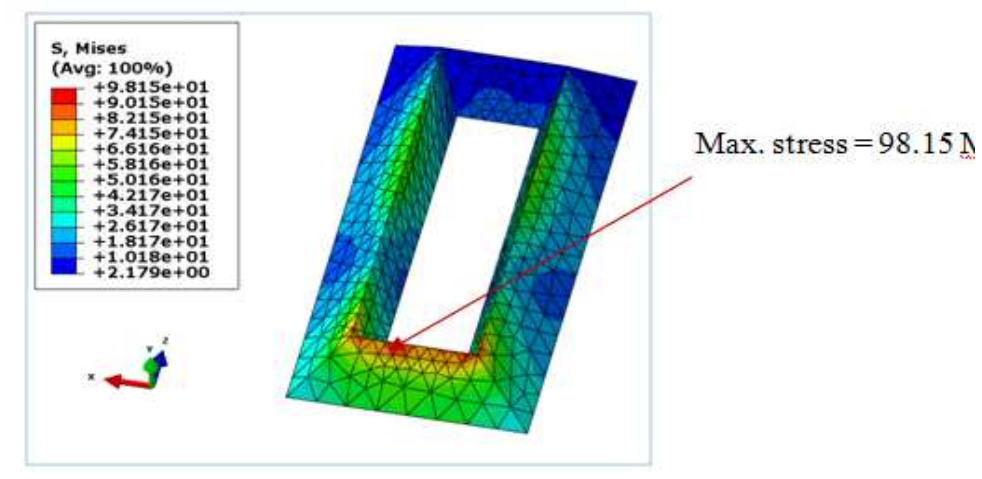

Figure 31: Von-Mises Stress Distribution in the Weld - Front Hook

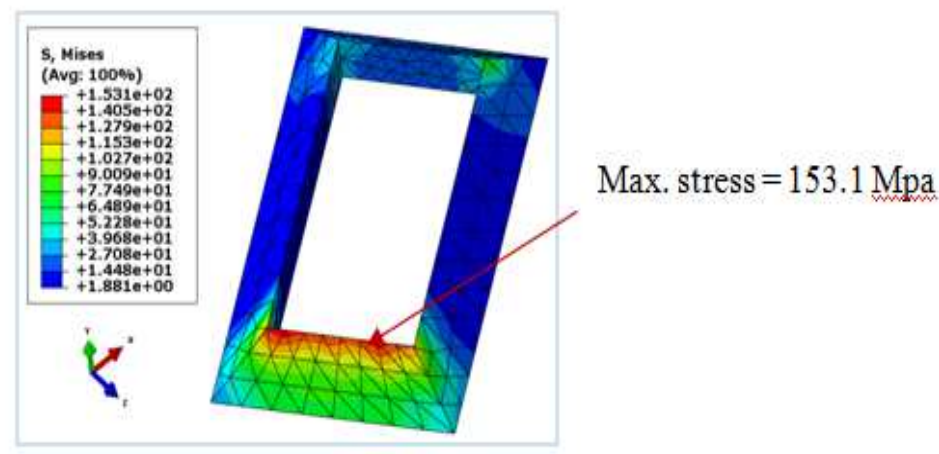

Figure 32: Von-Mises Stress Distribution in the Top Weld - LH Hook

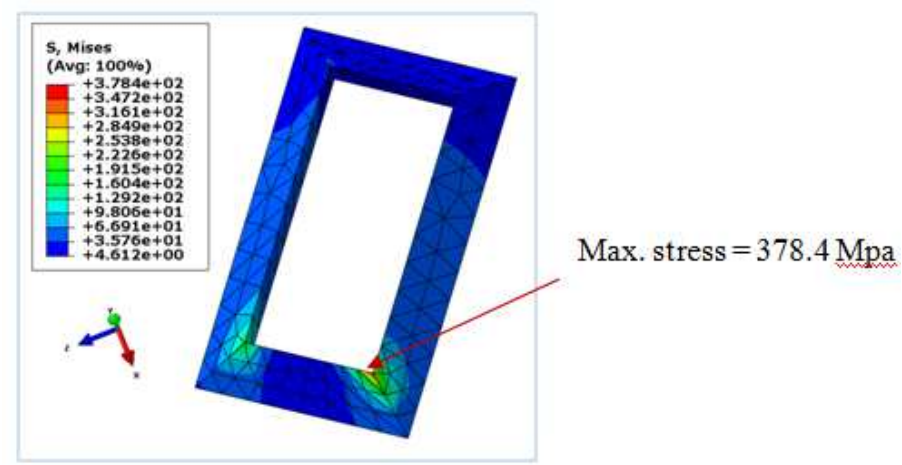

Figure 33: Von-Mises Stress Distribution in the Top Weld - RH Hook

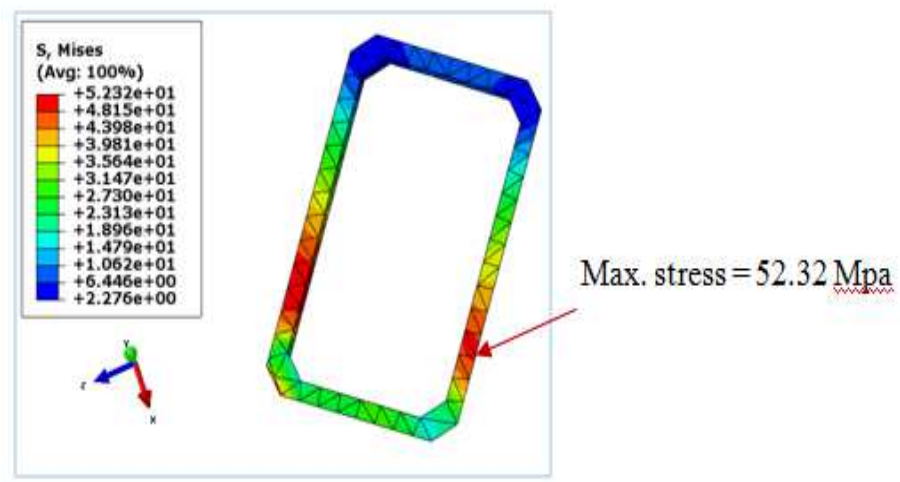

Figure 34: Von-Mises Stress Distribution in the Bottom Weld - LH Hook 


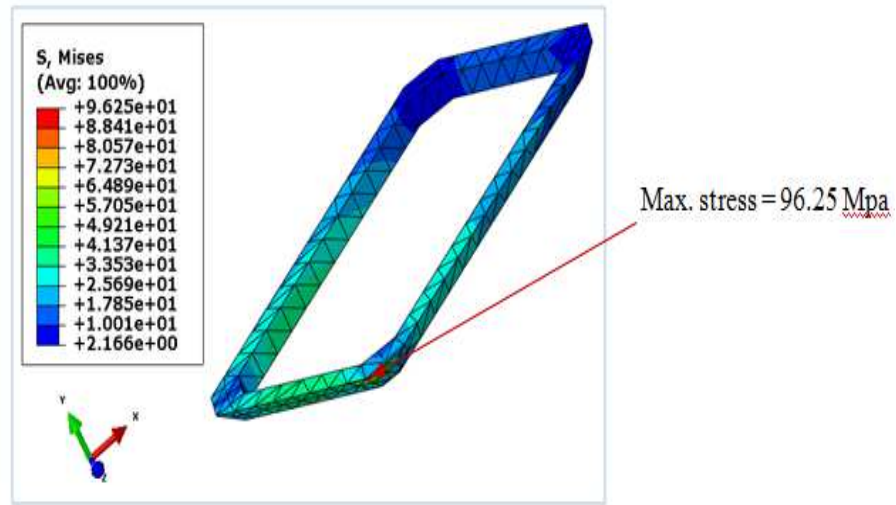

Figure 35: Von-Mises Stress Distribution in the Bottom Weld - RH Hook

As a result of Load case 2, the Von-Mises stress distribution on all the three D-Shackle pins for the Lifting Hooks and maximum principal stresses are shown in Figures 36 to 38. Peak stresses in the D-Shackle pin Front, LH and RH are $763 \mathrm{MPa}, 769 \mathrm{MPa}$, and $750 \mathrm{MPa}$, respectively.

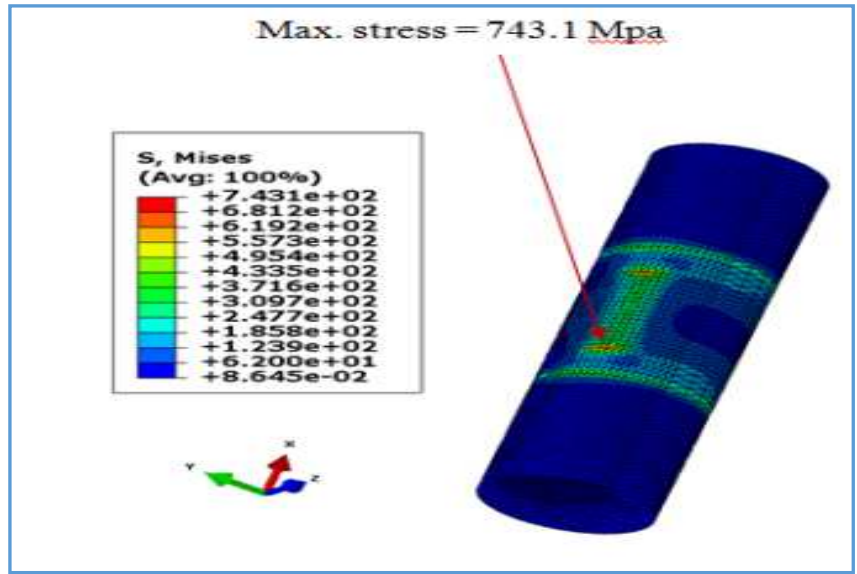

Figure 36: Stress Distribution in the D-Shackle Pin Front

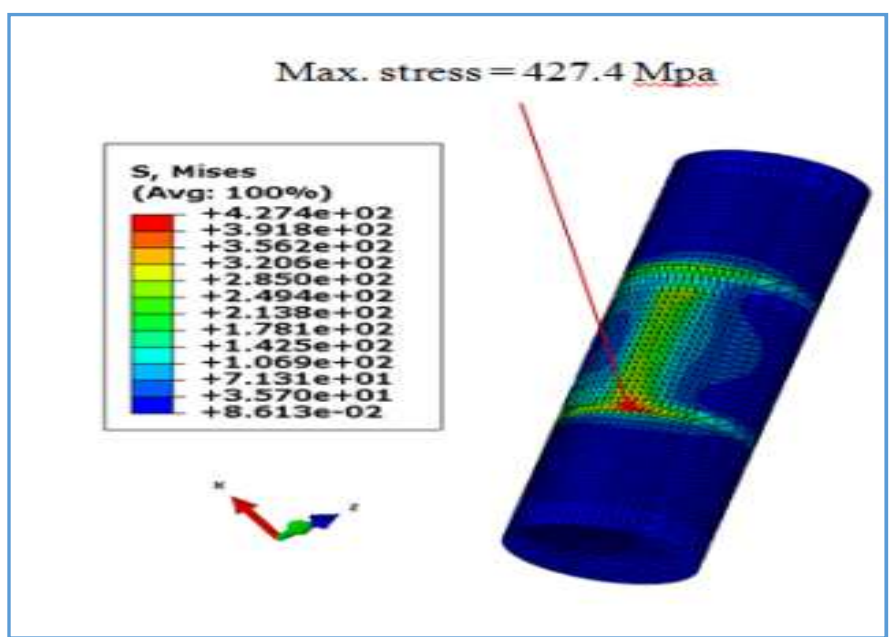

Figure 37: Stress Distribution in the D-Shackle Pin LH 


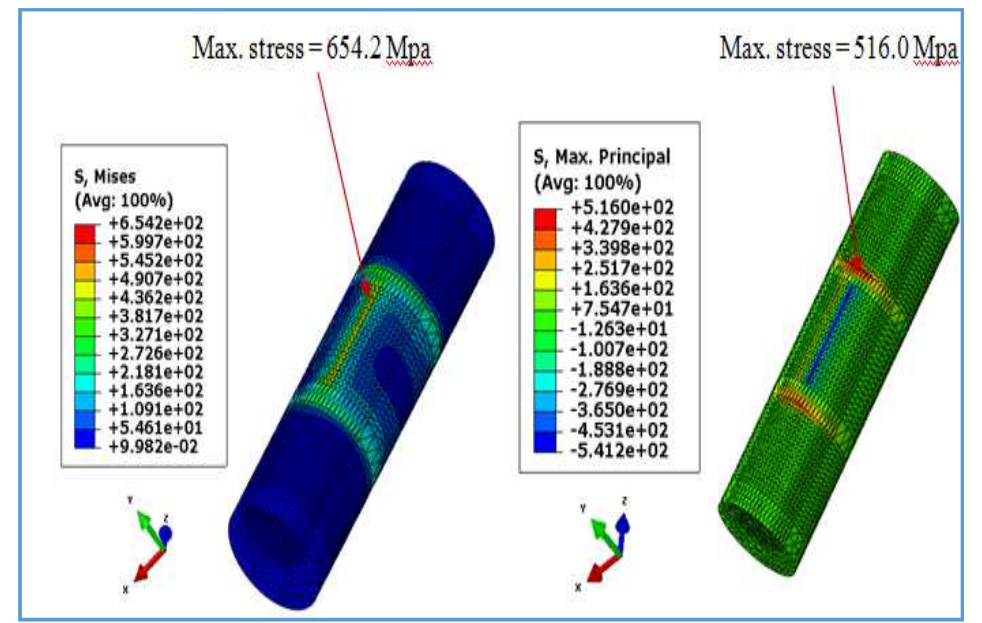

Figure 38: Stress Distribution in the D-Shackle Pin RH

\section{SUMMARY AND CONCLUSIONS}

Finite element model of Weld assembly of the modified Turret Lifting Hooks of the Combat Vehicle is prepared from the assembly solid model. The solid geometry of the weld assembly has meshed with C3D4 linear tetrahedral elements. Common nodes shared by the hooks and the Welds and by the Welds and the Plates are merged, in order to ensure the connectivity of the respective components with the respective welds.

Analysis has been done for two load cases as mentioned below:

Load Case 1: Static analysis of the Turret Lifting Hooks welding assembly of Combat Vehicle applied with a vertical hanging load of $215820 \mathrm{~N}$ (22 Tons of TWS mass) at the CG of TWS in order to simulate gradual lifting of the TWS.

Load Case 2: Static analysis of the Turret Lifting Hooks welding assembly of Combat Vehicle applied with $2 \mathrm{~g}$ acceleration load due to gravity in the vertical direction in order to simulate sudden lifting of the TWS.

From the results of the above said analysis of the weld assembly of modified Turret Lifting Hooks, it has been observed that in the Load case 1, ignoring the compressive contact stress, the peak Von-Mises stress value in the Lifting Hooks, Front, LH side and RH side are 154.5 MPa, 258.4 MPa and 145.2 MPa respectively, whereas the yield limit of the Turret Lifting Hooks material (Homogenous weldable steel armor to SPC CDA-99) is 800 MPa. Peak stresses in the top welds of the Lifting Hook Front, LH and RH are 50.82 MPa, 78.88 MPa, and 203 MPa. Peak stresses in the bottom welds on the lifting hook $\mathrm{LH}$ and $\mathrm{RH}$ are $27.72 \mathrm{MPa}$ and 50.16 $\mathrm{MPa}$ respectively. Details of stresses induced in various components in the Turret Lifting Hooks of modified weld assembly for both two load cases are shown in the following Table 3 .

Table 3: Summary of Stresses in the Turret Lifting Hooks Modified Weld Assembly in Combat Vehicle

\begin{tabular}{|c|l|c|c|}
\hline SI. No. & \multicolumn{1}{|c|}{ Description } & $\begin{array}{c}\text { Load Case 1 } \\
\text { Von-Mises Stress } \\
\text { (MPa) }\end{array}$ & $\begin{array}{c}\text { Load Case 2 } \\
\text { Von-Mises Stress } \\
\text { (MPa) }\end{array}$ \\
\hline 1 & Turret Lifting Hook Front & 154.5 & 313.6 \\
\hline 2 & Turret Lifting Hook LH side & 258.4 & 340.5 \\
\hline 3 & Turret Lifting Hook RH side & 145.2 & 277.3 \\
\hline
\end{tabular}




\begin{tabular}{|c|l|c|c|}
\hline 4 & Weld of Turret Lifting Hook Front & 50.82 & 98.15 \\
\hline 5 & Top weld of Turret Lifting Hook LH & 78.88 & 153.1 \\
\hline 6 & Top weld of Turret Lifting Hook RH & 203.0 & 378.4 \\
\hline 7 & Bottom weld of Turret Lifting Hook LH & 27.72 & 52.32 \\
\hline 8 & Bottom weld of Turret Lifting Hook RH & 50.16 & 96.25 \\
\hline 9 & D-shackle Pin Front & 491.4 & 743.1 \\
\hline 10 & D-shackle Pin LH & 276.6 & 427.4 \\
\hline 11 & D-shackle Pin RH & 513.9 & 654.2 \\
\hline
\end{tabular}

\section{Problem Size}

- Number of Elements: 392814

- $\quad$ Number of Nodes: 365011

\section{Software used for Modeling and Analysis}

- Solid Modeling: Pro/Engineer / Creo

- $\quad$ Finite Element Analysis: Abaqus CAE 6.13.2

\section{REFERENCES}

1. ASME Standard B30.2, "Overhead Gantry Cranes (Top Running Bridge, Single or Multiple Girder, Top Running Trolley Hoist)," 2005.

2. ASME Standard B30.9, “Slings Safety Standard for Cableways, Cranes, Derricks, Hoists, Hooks, Jacks and Slings,” 2006.

3. ASME Standard B30.10, “Hooks Safety Standard for Cableways, Cranes, Derricks, Hoists, Hooks, Jacks and Slings,” 2009.

4. Department of Labour of New Zealand, “Approved Code of Practice for Cranes,” 3rd Edition, 2009.

5. El-Shennawy, M., Omar, A. A., \& Ayad, M. Similar And Dissimilar Friction Stir Welding Of AA7075.

6. B. Ross, B. McDonald and S. E. V. Saraf, "Big Blue Goes Down. The Miller Park Crane Accident," Engineering Failure Analysis, Vol. 14, No. 6, 2007 pp. 942-961.

7. Yu Huali, H.L. and Huang Xieqing, "Structure-strength of Hook with Ultimate Load by Finite Element Method", Proceedings of the International MultiConference of Engineers and Computer Scientists, 2009 Vol II IMECS 2009, March 18 - 20, 2009 , Hong Kong.

8. “Advanced Mechanics of Materials", by A P Boresi and O M Sidebottam, John Wiley and Sons, 4th Ed. 1985, ISBN: 0-47184323-7.

9. DIN 15401 Part 1, Lifting hooks for lifting appliances; single hooks; Unmachined parts, Deutsche Norm, 1982.

10. Rashmi Uddanwadiker, "Stress Analysis of Crane Hook and Validation by Photo-Elasticity”, Engineering, $2011,3,935-941$.

11. Swalha, SALLAMEH., Al-Jarrah, J. A., Abu-Mansour, T., \& Gharaibeh, N. S. (2013). Mechanical properties of aluminium joints welded by friction stir welding. International Journal of Mechanical Engineering (IJME), 2(3), 77-84.

12. "Strength of Materials", by Sadhu Singh, 9th Ed. 2008, ISBN No: 81-7409-048-7.

13. DIN 15 400, Lifting hooks; materials, mechanical properties, lifting capacity and stresses Deutsche Norm, 1990. 
